\title{
Theories and Research in Educational Technology and Distance Learning Instruction through Blackboard
}

\author{
John Ronghua Ouyang*, Nile Stanley \\ University of North Florida \\ *Corresponding Author: rounghua.ouyang@unf.edu
}

Copyright $@ 2014$ Horizon Research Publishing All rights reserved.

\begin{abstract}
Educational technology is a fast-growing and increasingly developed subject in education during the past 50 years. The focus of the development of its theories and research is oriented into the methods and effectiveness of its implementation. This presentation is reviewing various educational technology related theories, exploring and discussing up-to-date theoretical research and applications. The related theories not only cover those mainstream and influential ones, such Behaviorism, Cognitivism, Constructivism, and Multiple Intelligence, but also include those extended and popular theories: Anchored Instruction, Cognitive Flexibility, Diffusion of Innovations, Elaboration Theory, Experiential Learning Theory, Script Theory, Situated Cognition and Symbol Systems Theory. The application is mainly to discuss the related theories and research in educational technology and pedagogy of DL instruction through blackboard. The pedagogy of DL instruction includes the course designing, module delivery and objective-oriented assessment strategies.
\end{abstract}

Keywords Education, Educational Technology, Distance Learning And Instruction, Blackboard, Online Education

\section{Introduction}

Educational Technology is increasingly developed. The $21^{\text {st }}$ century is featured with media technology. Educational Technology is playing a critical role in all fields of education. The development of computing and network technology, media technology, and particularly digitization, has been impacting our daily life all the time. As an electronic platform of distance education, "Blackboard" was developed in 1997, and has been widely utilized in web instruction and administration in elementary and middle/high schools, as well as in the colleges and universities. This paper is mainly to discuss the related theories and research of educational technology and the application of "Blackboard" in distance education.

\section{Educational Technology Related Theories}

Since the $20^{\text {th }}$ century, some major educational theories, such as Behaviorism, Cognitivism, Constructivism and Multiple Intelligence, have been widely implemented in education, greatly linked to the development and utilization of the educational technology. Ivan Pavlov (1949-1936), Russian biologist and psychologist, innovated behaviorism, Edward Thorndike (1874-1949), American educator and psychologist of Columbia University and Burrhus Frederic Skinner (1904-1990), one of the founders of American new behaviorism, further developed the behavior theory. Behaviorists believe external stimulation influences one's leaning behavior, rewards and punishment can change one's learning performance. Researchers and scholars confirmed that Behaviorism has greatly promoted and effectively implemented in programmatic instruction, and has strongly promoted and widely applied in computing-assisted-instruction and the development of educational technology.

Cognitive theory concerns those mental processes that cannot be observed through human beings' problem solving process and human beings' learning strategies. It studies human brains' thinking process. Cognitivists believe that a human being possesses intrinsic modes of receiving, processing and utilizing information at different cognitive development stages; advocate the study of people's cognitive development processes and models, and design different instructional programs based on one's cognitive development needs at different developmental stages. This theory is represented by Jane Piaget (1898-1980), Jerome Seymour Bruner (1915- ) and David P. Ausubel (1918-2008). In education, cognitive developmental theory is to develop students' capabilities of creative thinking, information analyzing, and problem-solving through computer-assisted instruction.

Constructivist theory is in favor of letting students to construct their point of view of the world, philosophy of living, technical expertise, and knowledge structures; emphasizes one's learning initiative, and social and 
situational learning experiences. The core of this theory is discovery learning. Students learn by doing. John Dewey (1859-1952), a well-known educational psychologist, believed that practicing is a foundation of learning, and without learning practice, students would get lost. He stressed that students construct their knowledge in practice, and instructional design should respect students' psychological development needs. Former Soviet psychologist Vygotsky proposed a social constructivist theory that emphasizes one's social and cultural backgrounds to determine one's behavior. He believed human's growth is a product of culture. The influence of Constructivist theory on the development and implementation of educational technology is mainly reflected in the pioneering educational games, multimedia development and dynamic online interactions.

The theory of multiple intelligences stresses everyone has his or her own unique intelligence. If curriculum, instructional contents, methods, and learning environment can fit into individual student's unique intelligence, the instruction and learning will become much more effective. According to research, currently there are nine multiple intelligence.

1) linguistic intelligence

2) logic-mathematical intelligence

3) spatial intelligence

4) bodily-kinesthetic intelligence

5) musical intelligence

6) interpersonal intelligence

7) intrapersonal intelligence

8) naturalistic intelligence

9) existentialist intelligence

Once Howard Gardner (1943) put forth the "multiple intelligence theory," this theory quickly caught the attention of educators and spread across the world. The research of this theory has positively promoted and guided effective use of educational technology to optimize individualized instruction.

In the United States, pragmatism is advocated. No matter it is "Behaviorism" that lunched initial scientific research on psychology or "Cognitivism" that focused its research on people's thinking process; constructivists' philosophy of "learning by doing" or multiple intelligences' unique contribution to children's intellectual development, these theories have obviously played an positive role in promoting the development and application of educational technology in American schools, and in the schools across the world; have left significant marks in the course of development of educational technology. Based on these theories, scholars have spawned a variety of technology-related educational theories, where well-known theories include "anchored instruction theory," "cognitive flexibility theory," "innovative diffusion theory," "elaboration theory," "experiential learning theory," "script theory," "situated cognition theory," "symbol systems theory" and so on.

Anchored Instruction Theory is taking the real life of the world as the core contents of teaching through educational media. Students discover, solve problems in the various means of the real living world. The reality of the living world is referred to as the "anchor," and the process of establishing and identifying the real living world to solve the problems is figuratively called "casting the anchor." "Anchored" instruction is one of critical instructional models under the constructive learning theory. It was proposed by a cognitive and technical team under the leadership of American professor John Bransford in Vanderbilt University in 1992. The Anchored Instruction Theory emphasizes technology-based learning. Students take the technology as the carrier, use the reality of living world as main contents to discover problems, generate questions, and ultimately solve the problems. Guided by the Anchored Instruction Theory, a famous example of the instruction is the "Jasper Woodbury Video Series." The Jasper Woodbury Video Series consists of 12 video adventures-CDs. Students identify and solve mathematical problems through those 12 adventure stories. Each adventure story is designed under the U.S. National Mathematics Framework Standards issued by the U. S. National Association of Teachers of Mathematics. Each video adventure-episode provides students with a variety of mathematical problem analyzing and solving opportunities. With those interactive and collaborative learning opportunities, students can obtain a mastery learning of natural sciences, social sciences, literature, history and other knowledge and skills.

Cognitive Flexibility Theory is proposed and advocated by Rand Spiro and others. This theory comes from cognitive theory represented by Jean Piaget (1898-1980), Jerome Seymour Bruner (1915- ) and David P. Ausulbel (1918-2008). Its adherents believe that the learning process takes place in complex and ill-structured domains. Cognitive flexibility theory holds that learning must have its specific environment, but it needs informational support from various fields. Instruction must be able to provide students with a variety of learning scenarios so that students have a vast space to construct their knowledge, and can take appropriate strategies to learn in a specific context. This theory greatly influences network and interactive technologies, and has been widely applied in medical and public health fields.

The Theory of Diffusion of Innovations aims to explain the model of receiving every innovation. In the field of educational technology, this theory is mainly applied in the educational technology training. The theory of diffusion of innovation describes the steps of technology innovation, process and characteristics of accepting new technologies, as well as receivers' role in the receiving process of technological innovation. Everett M. Rogers groups people, according to the degree of acceptance of innovation, into various stages: innovators, early adopters, early followers, late followers and laggards. Understanding the trainees' receiving capacities of new technologies can assist training institutions and trainers to design and deliver the training more effectively.

Distribution Cognition theory is similar to Social Constructivism theory. It emphasizes the accumulation of 
knowledge is not relied on the individual's effort, but depends on other people, learning environment and tools. It stresses that process of cognitive development can be distributed among the members of a social group, allocated between the internal and external factors along with the time of accumulating the knowledge. In the field of educational technology, this theory has been widely applied in distance education, computer-assisted collaborative learning and the development of computer-assisted-learning tools.

Dual-Coding Theory is a learning theory proposed by psychologist Allan Urho Paivio. According to the dual-coding theory, people's brain obtains information mainly through visual and auditory channels; people accumulate knowledge through processing, organizing and utilizing visually coded information and encoding spoken language. However, it depends on one of the information-obtaining channels, whether it is through the visual or auditory channel. Also it depends on whether ithasa capacity limitation of information processing within a certain time frame or has certain learning activities supported by the human brain. According to this theory, if one can receive similar amount and extent of information, intertwining and interacting through both visual and auditory channels, his or her learning can become much more effective. In the field of educational technology, Dual-Coding theory is more applied in multimedia learning and information-processing research.

Based on the Cognitive theory established by Jean Piaget, Jerome Seymour Bruner and David Ausubel, Charles Reigeluth and his colleagues proposed Elaboration Theory, an instructional design theory. According to the Elaboration Theory, instructional process and learning contents should be organized progressively from simple to complex, easy to difficult for improving the effectiveness of instruction and learning, and providing students with structured, meaningful, and mastery learning activities. Elaboration theory optimizes the effective instruction with seven implementation means: sequence of instructional and learning contents; learning steps preview; instructional review and support, comprehensive analysis, classification and comparison, cognitive development strategies, and students' self-control. Influenced by this theory, the development and implementation of educational technology in schools are mainly in technology supported instructional design of the contents and strategies, in the development of educational software, and in the organization of online instruction.

Experiential Learning Theory emphasizes the role of experience in learning. David A. Kolb and Carl Rogers, who promoted and applied the concept of "learning by doing" from John Dewey and Jean Piaget, proposed experiential learning theory. They believe learning occurred in two ways: cognitive learning and experiential learning. The former refers to people's learning isolated information through formal schools; while the latter emphasizes individual learners' participation in learning, their spontaneous learning and self-assessed learning. The core of experiential learning theory is the individual learner's learning participation and their experiences. Thus, the applications of educational technology in learning often encourage learners' participation, provide learners with immediate feedback and necessary help, and support learners with different learning needs.

Script Theory originally intended to explain language processing and deepen thinking skills. Later, this theory is used to explain story-comprehension steps, becomes contributable to the scope of cognitive linguistics. Although this theory emphasizes that people have their memorizing fragments which are related to a person's experience, people's memorizing fragments, or memorization "scripts" have a commonality, and this commonality can help people enhance their memorization. "Plots" are the basic elements of script theory. This theory has greatly influenced many computing programs' design, software development and organization of instruction.

Situated Cognition Theory puts forward that a person's cognitive development is of its own specific environment. That means one's leaning effectiveness is closely correlated with his or her learning activities, learning contents, and cultural background. Context is associated with whole situation, background, or environment. In other words, context refers to a person's social environment in which one's certain activity occurs, and is a necessity of one's social behavior. This theory emphasizes the influence of community life and social practice on one's cognitive development. In the fields of educational technology, this theory is mostly applied in educational games' design and development, scenario simulation and so on.

Symbol System Theory is proposed by Gavriel Saloman, an educational psychologist, to explain the different media influences on learning. Saloman believes different media symbol system impact media information delivery and learning effectiveness. The core of the symbol systems theory is that whether a media can effectively help effective learning depends on the degree of matching between the symbol systems and learners' learning contents and activities. Symbol System Theory has laid a theoretical foundation for the development and application of multimedia computation.

Educational technology is an interdisciplinary science to improve the instruction of a specific discipline, therefore, is subjected to the guidance and influence of various theories. According to the research, each theory has its own value of existence, belongs to a certain social domain, but no one theory can be taken as the best one (Ouyang and Zhao, 2007). In the discussion of which theory we should follow and apply it in the development and implementation of the educational technology in schools, we should only relate it to the basic connotation of a theory. More important, we should put more attention on the significance of a theory to improve the effectiveness of specific subject teaching and students' learning practice (Issorff \& Scanlon, 2002).

\section{Related Theoretical Research}

The number of theoretical research studies on education in 
general is reported voluminous; it is obviously more reported in Chinese. However, it is not the same case in the research on the educational technology related theories. In July 2013, through Google search, the authors found the index number of research citations on educational technology related theories was $10,800,000$ in Chinese, but $27,200,000$ in English. In addition to those numbers, it is worthwhile to share a comprehensive review of research on the educational technology related theories introduced above.

The theory and research are integral and indivisible. Educational technology designing and educational policy making need theoretical guidance; the development of a theory requires appropriate support from research (Maddux \& Cummings, 2004). History has proved that the development of educational technology impacts the development of education; the use of educational technology in the classrooms has opened a new page for instruction and learning. However, educational technology is only a tool. The effectiveness of using this tool depends largely on how instructors treat students' learning process and how they select educational technology related theories, and how they implement related theories in specific instruction.

Theoretical research pointed out that the strategy of optimizing instruction and learning guided by the theory of behaviorism is linear stimulus/response; scholars of cognitivism adopt information processing systems to optimize the instruction and learning and focus their studies on learners' thinking process; the instruction guided by constructive theory fully optimizes students' learning initiatives through using educational technology in instruction, so that students themselves can explore and construct their knowledge. Different theories support different instructional strategies, thus, the design, development and implementation of educational technology are also different. The strategy of linear stimulus/response was reflected in the instruction through radio, film and television in the 20th century, and in the development and use of drill and practice software and software packages in the $80 \mathrm{~s}$ of the 20th century. Cognitivism was popular during the $60 \mathrm{~s}$ and $80 \mathrm{~s}$ in the 20 th century. It stimulated the development of the personal computer system with the simulation of human brains' thinking process. The influence of constructivism on the development of educational technology in schools was mainly in late 20th century on the multimedia applications, online interactive learning and today's rapid emerging mobilization and handheld electronic devices which provide an instructional platform on which students can self-control learning contents, activities and progress without restrictions of time and space (Whelan, 2005).

Issoff and Scanlon (2002) have reviewed 30 years of research papers on the educational technology related theories and practice, discussed the influence of related theories on the artificial intelligence in education and the interactions between human being and computers. They believe that educational technology specialists, while engaging in the design of educational software and participating in the curricular development, should understand students' complex learning situations from multi-faceted perspectives and take schools' specific environment and students' cultural background into consideration. Different theories affect various disciplines at different times and places of teaching practice. Looking at the various theories, they divided educational technology related theories into two categories. One class is used to provide the guidance for the design of artificial intelligence system and interactions between human beings and computers and the development of effective instructional materials; another focuses on the education to help people understand different situated instructional cultures and the effects of educational technology on students' learning outcomes. The former enriches the content updating along with the development and utilization of educational technology and related experimental researches; the latter is relative stable, impacting our innovative instruction and curriculum, data analysis and instruction/learning assessment. The authors of this paper found that research on educational technology related theories are more focused on the application of educational technology in education.

Some scholars pointed out in the early 1980s that educational technology did not only refer to electronic devices, computers, it also became a branch of behavioral science. Educational technology specialists therefore cannot see a computer as an electronic device, but should link educational technology closely to the instruction and learning. The instructional environment mainly supported by computing technology has developed a new thinking of instruction and learning, and set new goals for education. Educational artificial intelligence system is designed to integrate the artificial intelligence projects into instructional environment, helping students learn with computing simulated instruction and the support a variety of learning theories. Artificial intelligence system in education has greatly impacted the development and application of educational technology. Research has shown that, since 1990s artificial intelligence in education has been developed to help people understand how to apply educational artificial intelligence effectively in instruction and learning from its original application of how to simulate theory-guided classroom instruction and leaning activities (Issroff \& Scanlon, 2002).

It has at least two points of view on the Situated Cognition Theory, neurophysiological and sociological. From the neurophysiological point of view, the process of constructing knowledge occurs simultaneously with learning behaviors. People construct knowledge through scenarios observing, talking with each other, and interaction of learning. From a sociological point of view, one's direct participation in social communication activities is the main way to construct new knowledge structures. Learning is a process of constructing knowledge; while learning scenario and social environment are the foundations of this process. With the development of computing technology, people construct knowledge often, even beyond, the classroom and 
the learning can often be obtained through online resources. Thus, there is a necessity to explore educational technology training function; to understand and consider learning scenarios and social environment before designing instructional tools and educational software. Scenario learning is related to our daily learning activities; our learning activities depend on our roles played in the community as community members, and depend on our series of learning behaviors that keep changing with the change of learning environment (Clancey, 1993, 1995).

According to Saloman's research, media symbol system applied to access of knowledge has multiple effects. First, media symbol system can particularly emphasize different instructional contexts. Second, media symbol system can maximize the convenience of information storage. Third, the different media symbol coding can help different psychological learners learn. Fourth, the media symbol system can meet different needs of information processing. Fifth, media symbol system can simulate human brain to store and process different information. Therefore, symbol systems to a certain extent determine how people obtain knowledge, access to what information and how much information. If media has no symbol system, it is the same as having no numeric numbers in mathematics (Moore \& Hall, 2009). Generally speaking, media can effectively optimize instruction and learning only when the media designing and information coding can meet people's learning needs and can be fit in instructional contents and learners' accepting abilities.

One of the researches on the anchored instruction theory mentioned above is the application of "Jasper Woodbury Video Series" in instruction. Jasper Woodbury's adventures are taught as instructional contents and Jasper Woodbury is the main character of those stories. A comparative study on anchored instruction was conducted in seven states in the south east of U. S. with 17 experimental classes and 10 control classes. The year-end test results of the study showed that experimental classes did much better than control classes, although experimental classes did not have extra training on solving mathematics word problems. Students in Jasper experimental classes can learn skills of solving mathematics word problems through exploring Jasper Woodbury's adventures. They significantly increased interest in learning mathematics, reduced the students' fear as they became more confident in their abilities of solving mathematics word problems and they felt more meaningful using mathematics to solve problems in daily life (Vye, 2009). Jeffrey W. Bauer (1998) conducted an experimental study on anchored instruction in three educational technology classes for six weeks. 48 pre-service teachers participated in the study. "Oregon Trail", very popular educational software, was selected as instructional material in a study of anchored instruction. Students explored the story of "Oregon Trail," acted as main characters in the story to explore and solve problems, and learned mathematics, history, geography, human customs and cultures. The results of the six-week experimental study showed that students who participated in the experimental study mastered those technology skills needed for instruction and learning, understood the anchored instruction theory and its applications in learning, mastered educational technology integration and classroom teaching skills. However, the design of educational technology software and instructional system under the guidance of anchored instruction theory must be around a series of case studies and scenarios of problem's questioning and answering; instructional materials must enable students to explore the learning with personal involvement, and provide students interactive learning spaces (Bransford \& Stein, 1993; CTGV, 1993).

According to Rogers' Theory of Diffusion of Innovations, those early technology users tend to accept new technology faster than those late technology users. The theory of diffusion of innovations is widely applied in educational technology training. Its application value is that the training department and trainers are able to match the training plan and design with trainees' beliefs, attitudes and motivation to accept new technology. When teachers and students are exposed to new educational technologies, their beliefs and understanding of new technology determine the degree of their acceptance of the new technology. Therefore, while school or training department introduces and promotes newest features and functions of a new educational technology to teachers and students, one of the effective strategies is to maximize the use of real instructional cases in classrooms to demonstrate the strengths of educational technology in improving the effectiveness of instruction and learning, fully promoting instructors' teaching and students' learning motivation and helping teachers and students maintain a good state of mind and a positive learning attitude.

Information Processing and Cognitive theory is originally a theoretical pillar in the interactive learning between human beings and computers. But recently, researches have shown that models of people's interaction with computers are impacted by a variety of theories. For example, because an analysis of a cognitive unit is far beyond the framework of individual's cognitive process, distributed cognition theory has also laid a theoretical foundation for the interactive learning and research between human beings and computers. One's cognitive development not only depends on one's learning behaviors, but also relies on one's cognitive understanding and cultural background (Hollan, Hutchins \& Kirsh, 2000). The purpose of human-computer interaction in learning process has not been changed; however, scholars and researchers have a common recognition with the cultural, environmental and other impacts on the learning process, and have applied these factors into the assessment of human's interactive learning through computers. Some scholars also find that, originally, the human-computer interactive learning was limited by specific discipline and specific instructional objectives, and only cognitive theory was applied in the research on the human-computer interaction models. But currently human-computer interaction becomes increasingly diverse, theoretical 
influences on the research of human-computer interaction are increasingly multiplied. Meanwhile, theoretical research design becomes involving more disciplines and various theories. In addition to cognitive psychology, the research design has included archeology, film studies, sociology and others; besides cognitive theory, research design has also adopted "distributed cognition theory," "external cognition theory," "interactivity framework, and other psychological theories (Issroff \& Scanlon, 2002).

Cognitive Flexibility Theory is from Cognitive Theory. It mainly aims at helping learners obtain the ability to understand a variety of scenarios, focuses on illustrating cases' internal relations and components. It helps establish a hypertext computer assisted instruction environment (Graddy, 2001; Chikatla \& Reese, 2009). Research found this theory has a great impact on the design of interactive educational technology, multimedia, video and hypertext medium of instruction, making multi-level, multi-mode instruction become true, and having educational technology-supported knowledge linked to provide multiple instructional cases and models, and integrate dynamic instructional environment in daily life (Chikatla \& Reese, 2009). Steps of cognitive flexibility theory-based instruction include: 1) students are divided into small learning groups; 2) each group discusses their findings and questions with instructor; 3) students collaboratively explore knowledge and questions needed for solving the problems; 4) instructor provide students with necessary knowledge and scenario analysis for solving those problems; 5) students apply their mastered knowledge to learn specific cases and solve problems; 6) students apply what they have learned from old cases to learning new knowledge in new cases (Chikatla \& Reese, 2009).

Alty (2002) conducted a study on the application of Dual-Coding Theory with a "text" only group, "text + graphics" group and "graphics + audio" group. He found that different combination of media were associated with different effectiveness of instruction. Despite that there was no significant difference among three groups when easy contents were taught, but along with the deepening the difficulty of instructional contents, the effectiveness of instruction turned out significantly different. The mean of overall achieving scores of "Graphics + Audio" group showed $14.3 \%$ higher than that of "text + graphics" group and $21.5 \%$ higher than that of "text" only group. The results of Alty's experimental study also showed different media had different effects for students with different learning styles. "Graphics + Audio" tended to be multiply beneficial to those audio-visual learners. People's memory system consists of three parts: information receiving, information coding and storing, and information retrieving. Therefore, some scholars suggest that multimedia courseware designers should consider using effective text and visual materials to maximize the learning through textual and visual media, and minimize those unrelated cognitive distractions (Mayer, 2005).

Elaboration Theory once was a theoretic innovation in 1980s for instruction design. It proposed a progressive approach, from easy to difficult, for instruction designing, sorting, analyzing, reviewing and summarizing. Some scholars believe that the value of this theory is not the theory itself, but its application in designing progressive instruction with a series steps. Therefore, some scholars have suggested diluting detailed theoretic steps in instruction designing, getting rid of unnecessary restriction in the designing process and determining basic framework and sequences of instruction in accordance with students' understanding the contents of instruction (Wilson \& Cole, 1992). At the end of 1990s, Reigeluth, advocator of elaboration theory, began to stress overall learning process and students-centered instructional models, and get away from learning tasks-centered and content-centered designing models and sequential instruction (Regan \& Smith, 2004).

Menaker et al. (2006) believes that when new educational technology optimizes instruction, it requires our understanding and utilizing "Experiential Learning Theory." Applying experiential learning theory in computer-assisted instruction and educational game and scenario-simulation design is one of effective ways to optimize instruction. But understanding experiential learning theory is the foundation of optimizing instruction and learning environment. Relying on one's experience alone, one cannot effectively acquire knowledge, develop thinking skills and improve problem-solving and decision-making skills. The implementation of experiential learning theory requires us to create an optimal learning environment. Experiential learning environment is designed to provide learners opportunity to construct experimental knowledge structure, knowledge feedback and update to optimize instruction. The key is that we must be able to effectively balance the "discovery instruction" design and "heuristic-guided instruction" design. Today, supported by the rapid development of educational technology, creating experiential learning environment is no doubt an effective strategy to optimize instruction with integration of technology and experience. However, this strategy is a double-edged sword. If the experience is without support of appropriate educational technology and well-designed instruction, the effectiveness of experiential learning would be counterproductive.

Maddux and Cummings (2004) found that educational technology had its thriving splendor in the past half century, but it had short-lived doom. The latter is quite common in the field of education. Some very creative and potential new technologies died out even before they were put onto the market to compete against the fray. One reason was the lack of a transition of results of research to instructional practice in education. The other was teacher education could not make pre-service and in-service teachers recognize and understand the importance of research. In addition, teachers and school administrators tended to ignore educational research, were lacking in skills of conducting educational research, and could not correctly assess research findings. Some education researchers, in order to pursue the numbers 
of publication, ignored the quality and significance of research to guide instructional and learning practice. However, the misfortune and short-lived doom of new educational technology and educational software in educational practice in schools were mainly caused by the lack of a foundation of applied research on educational technology related theories; instruction and learning in the classroom were lacking in the theoretical guidance of using effective educational technologies. The authors of this paper believe that the research on the educational technology related theories should be able to be applied into educational practice to optimize the instruction and learning. The significance of a theory cannot only be determined by its own theoretical underpinnings, but should be examined by its application effect on the effectiveness of instruction and learning.

\section{An Application of "Blackboard" in Distance Instruction and Learning}

"Blackboard" was founded in 1997. In 1998, "Blackboard" merged with "CourseInfo LLC" to form the Blackboard Inc., and launched CourseSite, a free course system for faculty. In 2006, it brought its competitor WebCT Company. Since then, the company marketed widely its course developing and managing system for distance instruction in higher education and in elementary and middle schools. "Blackboard" consists of a full-featured online instruction toolkit modules: "Comprehensive Teaching and Learning Tools," "Immersive Collaborative Learning," "Multi-modal Connection," "Campus Commerce Secure Transact," "Actionable Data Analysis and Reporting," "On-the Go Mobile Connectivity," and "Easy-to-use All-in-one web-based learning and engagement."

The "Comprehensive Teaching and Learning Tools" module provide instructors with full-featured online instructional tools to design course instruction, deliver instruction contents, and manage students' learning achievement. These tools provide students with more conveniences to access learning materials and obtain the instruction without time and location restrictions, complete required learning program discipline, and engage in life-long learning to fulfill themselves. In the content area of Blackboard, instructor and students can achieve the completion of course design, course instruction and learning. "Immersive Collaborative Learning" module on the blackboard provides instructor and students with a platform of collaborative instruction and learning, helping, supporting and sharing each other. The "Multi-Modal Connection" module is a platform of communication between one to one, one to group, and group to group for an online instruction. This is commonly through email, chat room and discussion board on the blackboard. The "Campus Commerce Secure Transact" module is to provide a safe and secure online instruction. Each school, discipline and course can set up specific password permission access. Instructors and students who participate in online instruction must get appropriate permission and password to gain access to those permitted areas of instruction and learning on the blackboard. The "Actionable Data Analysis and Reporting" module in the blackboard is to provide the instructor and students with feedback and achievement data analysis to improve the effectiveness of instruction and learning. The "On-the-Go Mobile Connectivity" module makes online instruction completed through cell phone, laptops and mobile devices. The "Easy-to-Use All-in-One Web-based Learning and Engagement" module on the blackboard helps instructor and students complete synchronous and asynchronous online instruction, share instructional resources, and interact through instruction and learning. All these Blackboard modules have their own specific function and, meanwhile, they support each other to support instruction and learning online.

TSL6350 is a graduate online course in the area of "English as a Second Language" at the University of North Florida. The Blackboard's application in this course includes eight sections, "Orientation", "Syllabus", "Weekly Learning modules", "Discussion Board", "Assignments", "My Grades", "Tools", "Help and Support" (Figure 1).

In the "Introduction" section", the instructor provides overview for the students which include the courses design, instruction arrangements and necessity of technological skills. The "Syllabus" is considered as an informal contract between instructor and student, a blue print of instruction. It concisely describes course goals, instructional objectives, course contents, learning activities, assignment requirements, learning assessment, instruction and learning resources, and instructor's contact information. "Weekly Learning Modules" is a major section for the course instruction (Figure 2). It specifically details weekly instruction contents, learning activities, and learning assessment. In this section, instructor details instructional objectives, contents, and related readings, and instruction and learning activities. It includes synchronous and asynchronous lectures, small and big group discussions, learning and resources sharing, and collaborative learning activities. Meanwhile, it provides learners with weekly learning assignments and assessments, supplemental instructional materials for enhancing the effectiveness of learning (Figure 3). 


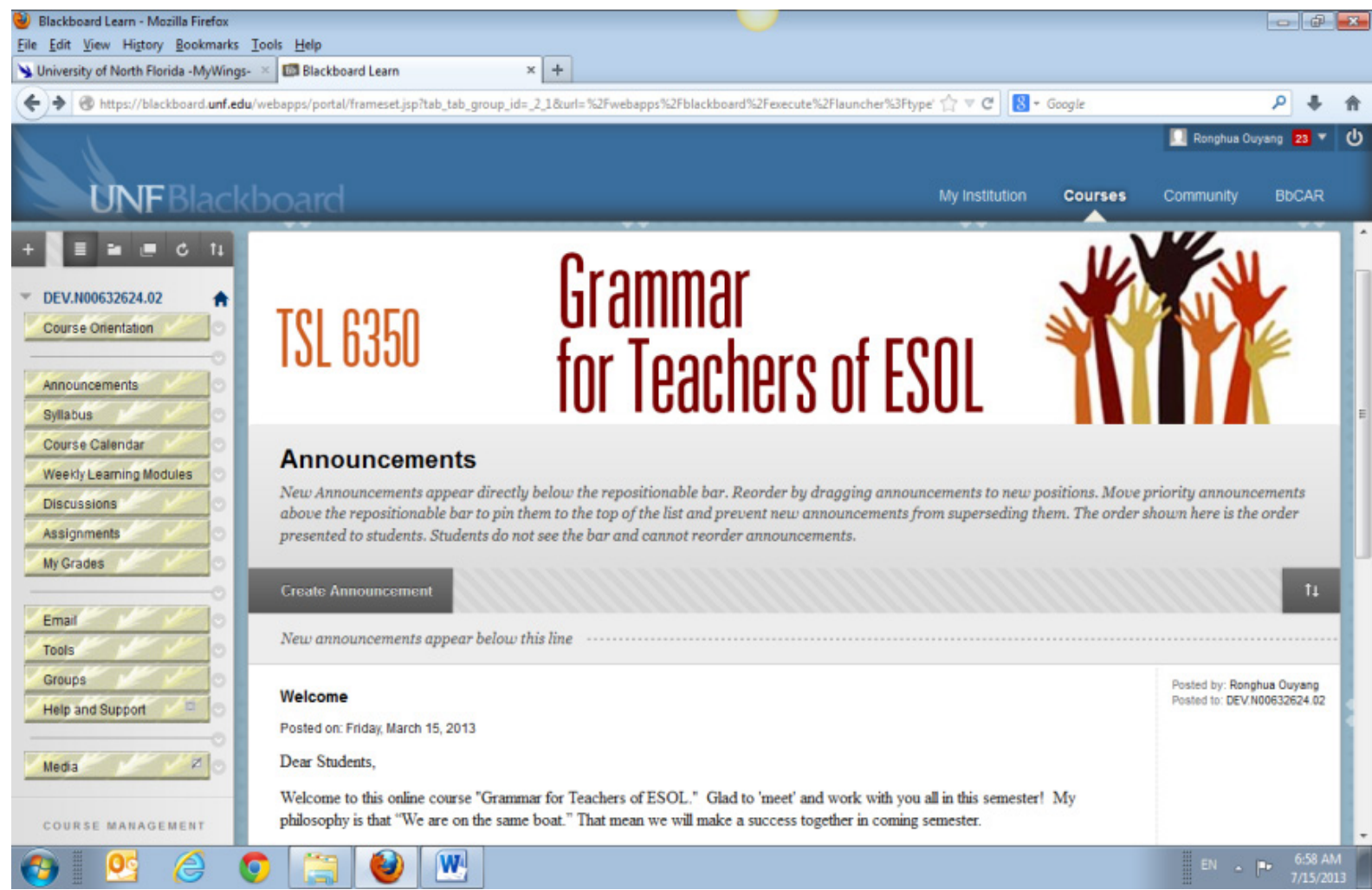

Figure 1. Home Page of Online Course-TSL6350

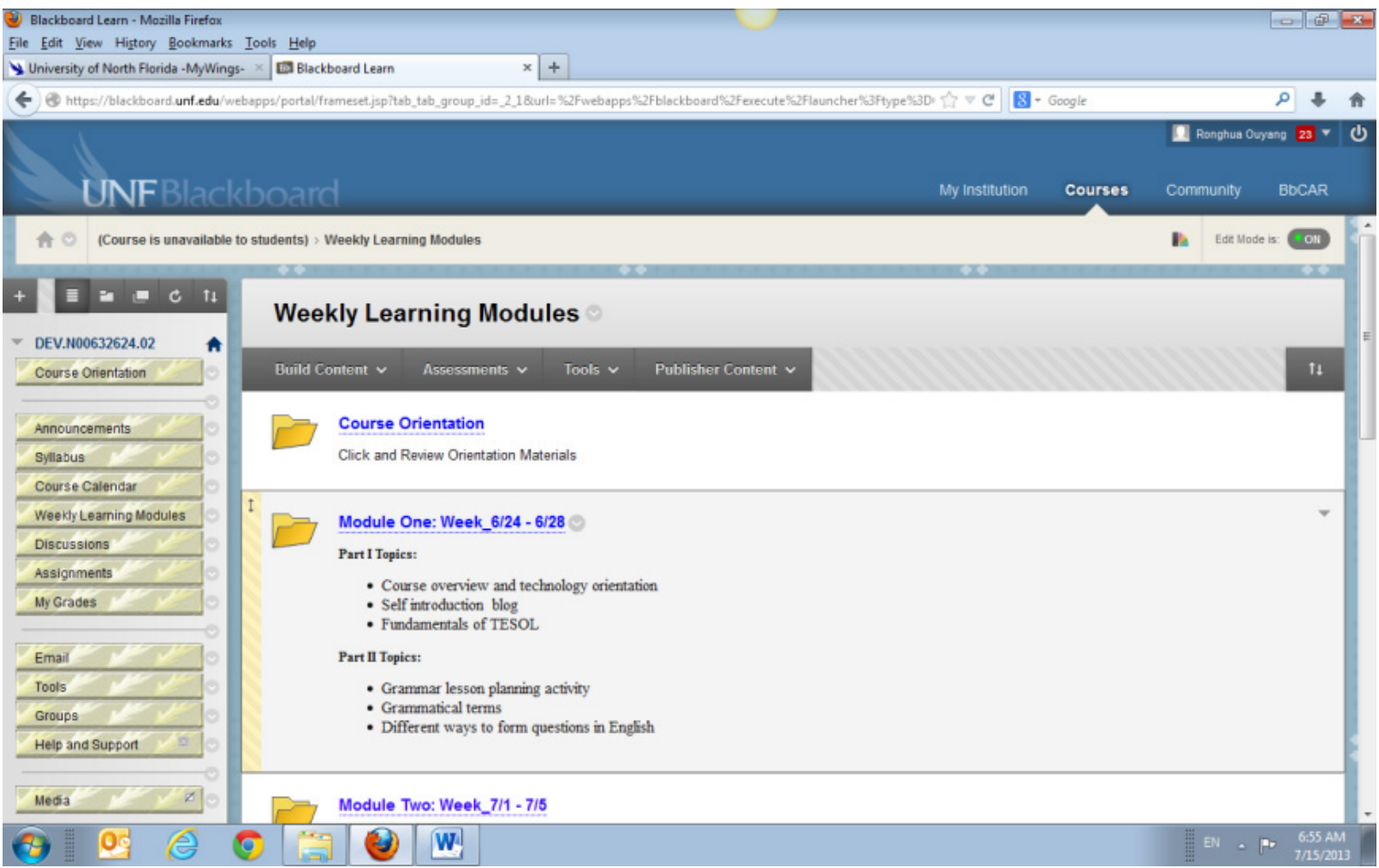

Figure 2. Outline Page of Weekly Learning Module 


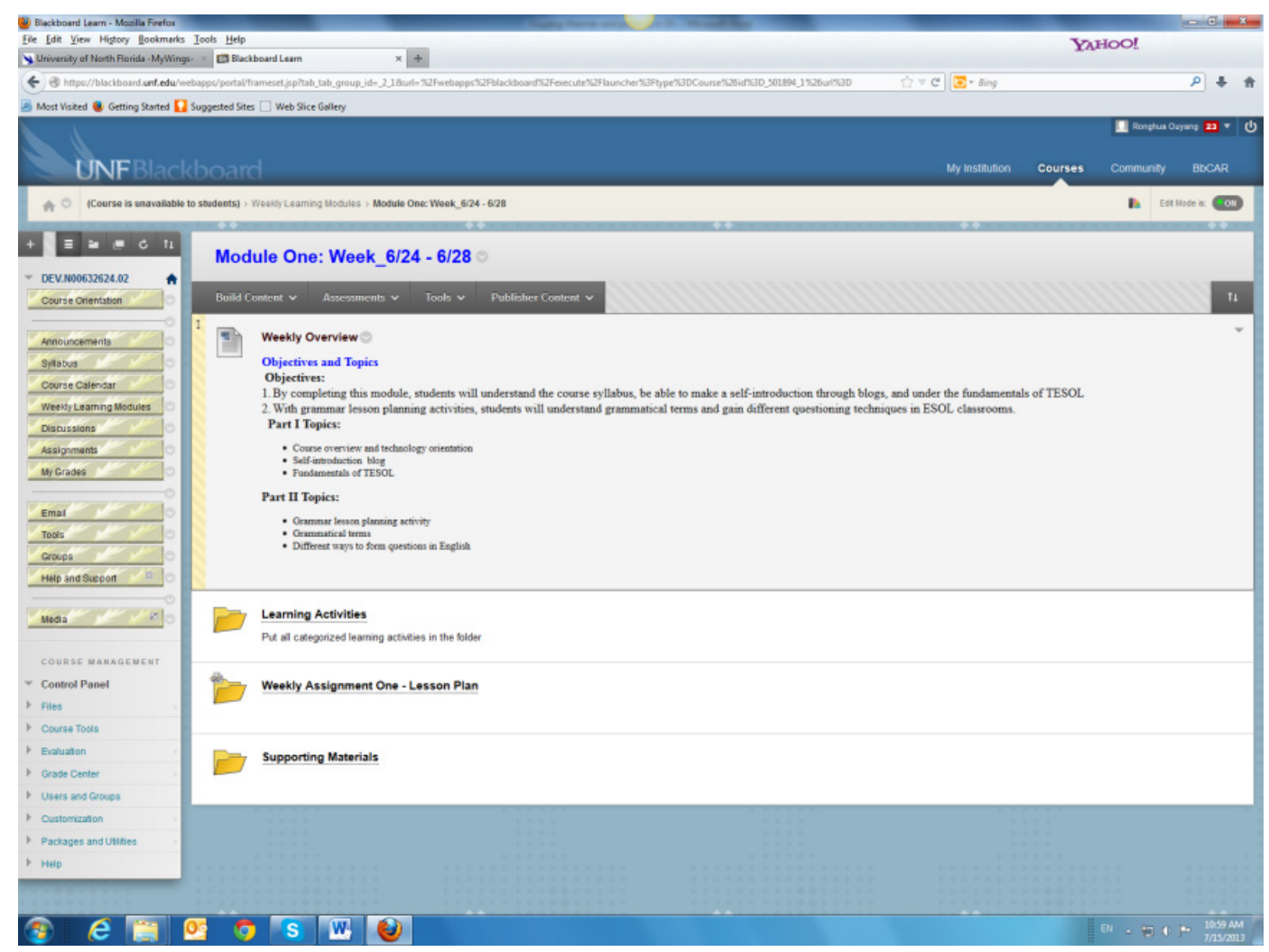

Figure 3. Detail Page of Weekly Learning Module

"Discussion Board" is the section to provide learners a platform to discuss weekly readings, learning and related topics. It also includes student-centered learning assessment criteria, weekly discussion's starting and ending dates and time (Figure 4).

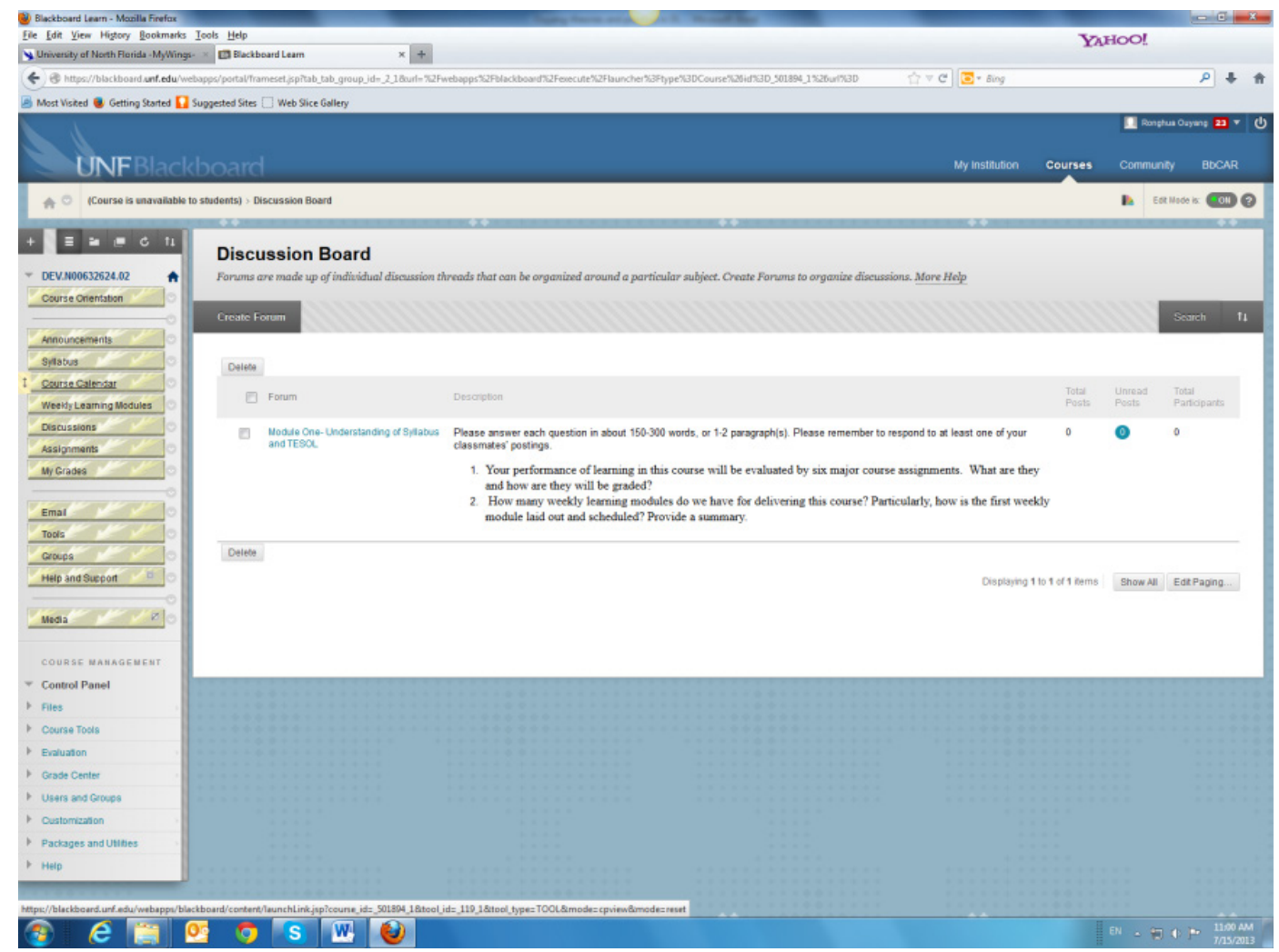

Figure 4. Discussion Board Page 


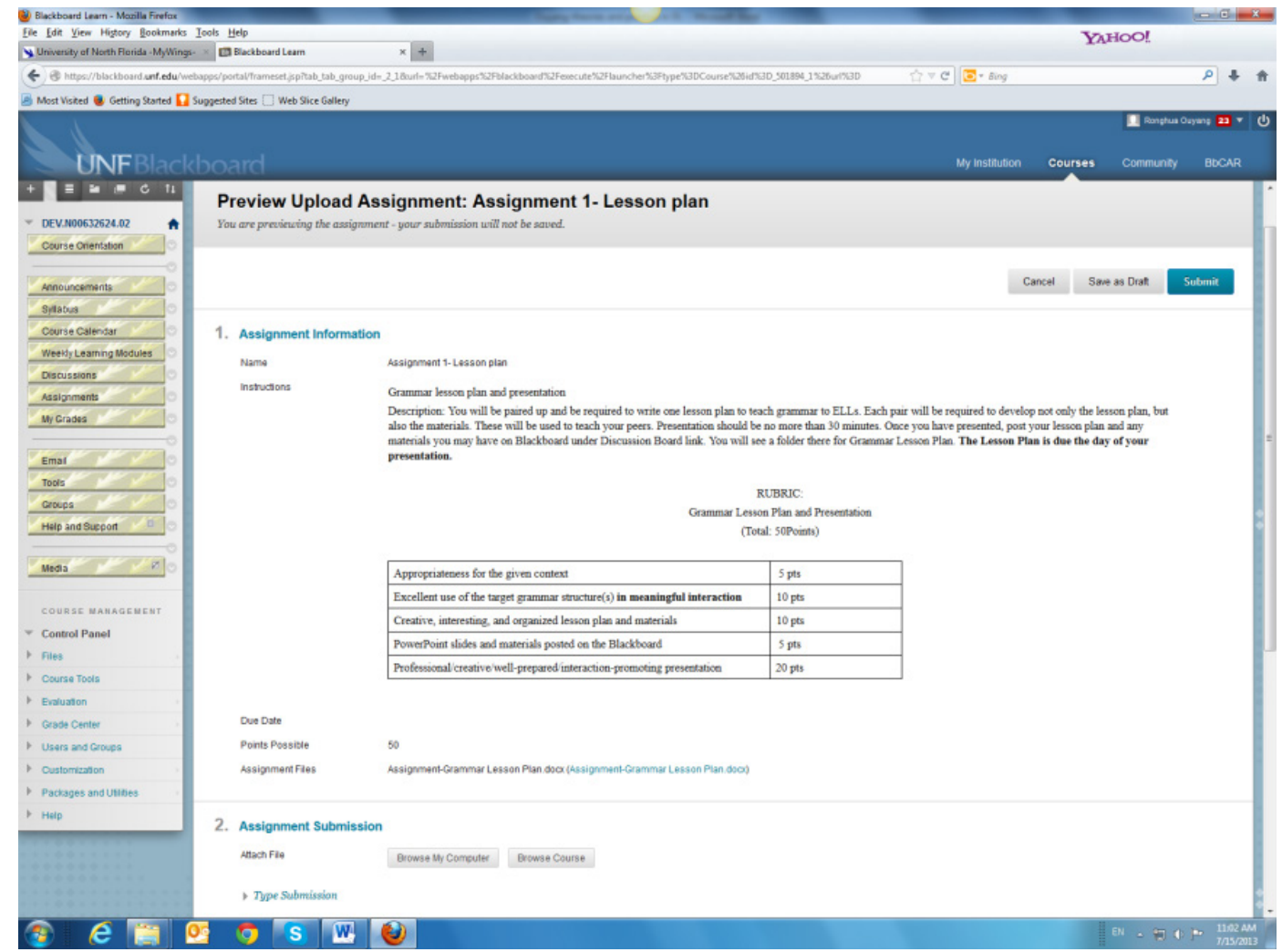

Figure 5. Assignments Page

"Assignments" section includes detailed descriptions of weekly assignments and projects, assessment criteria, and the submission links. It also sets up clearly the due date and time for each specific assignment, provides timely feedback, and offers necessary help and support (Figure 5).

"My Grades" is the place recording students' learning achievements, helps the instructor understand students' leaning progress and effectiveness of instruction, so that instructor can adjust instruction strategies and contents; students can improve their learning behavior and manage learning time better, and optimize the learning. For supporting students' learning, this course provides common links of network tools for online learning. In addition to commonly used "email", "discussion board", it includes the links of "blackboard blog", "blackboard Wiki", and "white board and presentation" for synchronous instruction and discussion. In order to fully exploit the advantages of educational technology, this course has also opened up a "Help and Support" section to strengthen teacher-students, students-students interaction and collaboration in instruction and learning.

\section{Conclusion}

Along with the increasingly developed and innovated computing technology and web technology, education in the 21 st century is facing the challenges of newly developed technologies. In the United States, educational technology has entered the classrooms at the elementary, middle and university levels, has been applied in various educational training and management departments. CAI, online instructional design, development of educational games, and educational technology training and etc. have become an indispensable part in the education. Theoretical research related to the educational technology, therefore, should be naturally evolving into a flourishing, enthralling and time-adapting era. However, we are still lacking of the theoretical research on educational technology, especially, the research on the interaction between human beings and computers, on the educational artificial intelligence design, and development design of instructional materials and educational games system. It still requires educators' and scholars' continuous exploration; and educational technology designers' and specialists' continuous engagement in the research. Numerous educational technology theories have been approved with their unique impact and great significance in specific technology areas, media design, and educational technology applications in instruction and learning, but none of them can be labeled as the best one or a universal theory. Thus, we should select appropriate theory for its application in education to meet different learners' learning needs, to mesh with different instructional contents and environment. Instructors should explore and select appropriate theories and effective educational technologies to optimize instruction and students' learning.

Educational technology is increasingly developed; related researches keep evolving. Without appropriate theory as the guidance, educational technology design and educational 
technology-assisted instruction would become lost. An aspiring instructor must be able to correctly and flexibly use a variety of educational theories in order to make his or her instruction more effective. Confucius said, "Words without literary talent will not become popular". For the same token, without appropriate theoretical guidance, instructors will only be bound instruction in personal experience, and will lack of creative thinking. Even with certain cases of success of effective instruction, it is only by accident, and such chances are seldom. Instructors will often fail to reach his or her expectations for the degree and depth of effective instruction. Similarly, without the support from specific designs and instructional practice through educational technology, those theories will be of no significant value. "Blackboard" is an effective online instruction platform with fully featured functions for instructional management, course design and development, assessment and instruction/learning interactions. However, it is only one of tools that can be adopted for distance education. As an educator who is engaged in distance education, he or she should explore, evaluate and select appropriate educational technology theories and be able to effectively design online curriculum and instruction in accordance with specific learners, instructional situations, materials, goals and objectives. Standing on the shoulders of giants, an online instructor should be able to fully use his or her wisdom and talent to improve technical design and quality of instruction, and to optimize effectiveness of instruction and learning in the classrooms. If we can have an in-depth understanding of a variety of educational technology related theories and can effectively and flexibly implement Blackboard's various functional features in instruction, we believe that advanced educational technology will certainly become more effectively and widely developed and implemented in the 21 stcentury's online education.

\section{REFERENCES}

[1] Alty, J. L. (2002). Dual coding theory and commuter education: Some media experiments to examine the effects of different media on learning. Ed-Media 2002 World Conference on Educational Multimedia, Hypermedia \& Telecommunications proceedings. Denver, Colorado. Retrieved December 18, 2010, from http://www.eric.ed.gov/PDFS/ED476964.pdf

[2] Bauer, J. W. (1998). Anchored instruction in pre-service educational technology class: A research project. In SITE 98: Society for Information Technology \& Teacher Education International Conference Proceedings. Retrieved December14, 2010, from http://www.eric.ed.gov/PDFS/ED4 21116.pdf

[3] BlackBoard (2013).Education technology solutions for all. Retrieved July 8, 2013, from http:/www.blackboard.com/Platforms.aspx

[4] Bransford, J.D. \& Stein, B.S. (1993).The Ideal Problem
Solver (2nd Ed). New York: Freeman.

[5] Chikatla, S. \& Reese, R.(2009) Cognitive flexibility theory. Retrieved June 14, 2009, from

http://www.southalabama.edu/oll/mobile/theory_workbook/c ognitive_flexibility_theory.htm

[6] Clancey,W.J. (1993) A situated cognition perspective on learning on demand. Proceedings of Fifteenth Annual Conference of the Cognitive Science Society, Boulder, Lawrence Erlbaum Associates, 181-183.

[7] Clancey,W.J. (1995) A tutorial on situated learning. Proceedings of the International Conference on Computers and Education (Taiwan) Self, J. (Ed.) Charlottesville, VA: AACE. 49-70, 1995.

[8] CTGV (1993). Anchored instruction and situated cognition revisited. Educational Technology, 33 (3), 52- 70.

[9] Hollan, J., Hutchins, E. and Kirsh, D. (2000) Distributed Cognition: Toward a New Foundation for Human-computer Interaction Research, ACM Transactions on Computer-Human Interaction, 7(2), 174-196.

[10] Mayer, R.E. (2005). Cognitive theory of multimedia learning. In Richard Mayer (Ed.),The Cambridge Handbook of Multimedia Learning, (pp.31-49). Cambridge, England: Cambridge University Press.

[11] Maddux, C. \& Cummings, R. (2004).Fad, Fashion, and the Weak Role of Theory and Research in Information Technology in Education. Journal of Technology and Teacher Education. 12 (4), pp. 511-533. Norfolk, VA: AACE. Retrieved from http://www.editlib.org/p/4032.

[12] Menaker, E., Coleman, S., Collins, J., and Murawski, M. (2006). Harnessing experiential learning theory to achieve war-fighting excellence. Paper presented at the Interservice/Industry Training, Simulation \& Education Conference,

http://www.idsi.com/downloader/download.aspx?fileID=773

[13] Moore, S. \& Hall, E. (2009). Review of interaction of media, cognition, and learning by Gavriel Salomon. Retrieved April 12, 2009, from http://novationsjournal.org/content/original_s tory.pl?story $=6$

[14] Ouyang, R. \& Wang, X. (2011) (Eds.) Educational Technology. Beijing, China: Renmin University Press. ISBN 978-7-300-12930-3.

[15] Ouyang, R., \& Chan, T. C.(2007) (Eds.) Education. Beijing, China: China Renmin University Press. ISBN 978-7-300-08228/C.381.

[16] Issroff, K. \&Scalon, E. (2002). Educational technology: The influence of theory. Journal of Interactive Media in Education. Retrieved March 14, 2009, from http://www-jime.open.ac.uk/2002/6/.

[17] Regan, T. \& Smith, P. (2004) Conditions theory and models for designing instruction. In David $H$. Jonassen (Ed.) Handbook of research on educational communication and technology (2 ${ }^{\text {nd }}$ Ed.)(pp.623-645). Mahwah, NJ: Lawrence Erlbaum, Inc.

[18] Theories in Educational Technology (2009).Retrieved March 14, 2009, fromhttp://www.coe.ufl.edu/school/edtech/theories .htm 
[19] Vye, N. J. (2009). Instructional design-Anchored instruction. Retrieved June 14, 2009,

fromhttp://education.stateuniversity.com/pages/2090/Instruct ional-Design-ANCHORED-INSTRUCTION.html\#ixzz0KP RKJeS6\&D $\backslash$

[20] Whelan, R. (2005). Instructional technology\& theory: A look at past, present \& future Trends. Retrieved June 14, 2009 , from http://www.nyu.edu/its/pubs/connect/spring05/pdfs/whelan_i t_history.pdf

[21] Wilson, B., \& Cole, P. (1992).A critical review of elaboration theory. Educational Technology Research and Development, 40 (3), 63-79. 